\title{
Health Status and Programs Implemented by the Provincial Government of Catanduanes in Bicol Region, Philippines
}

\author{
Marilyn B. Panti \\ College of Health and Sciences, Catanduanes State University, Virac, Catanduanes, Philippines \\ Email: bingbpanti@yahoo.com
}

How to cite this paper: Panti, M. B. (2020). Health Status and Programs Implemented by the Provincial Government of Catanduanes in Bicol Region, Philippines. Open Journal of Social Sciences, 8 , 419-431.

https://doi.org/10.4236/jss.2020.85029

Received: January 28, 2020

Accepted: May 26, 2020

Published: May 29, 2020

Copyright $\odot 2020$ by author(s) and Scientific Research Publishing Inc. This work is licensed under the Creative Commons Attribution International License (CC BY 4.0).

http://creativecommons.org/licenses/by/4.0/

\begin{abstract}
As the world grapples with various health threats and pandemics, implementation and assessment of the delivery of health services especially in emerging economies is vital to promote health accessibility, coverage, quality and continuity. This study determined the status in the actual service delivery on health implemented in the Rural Health Units (RHU) of Catanduanes, a typhoon-prone area in the Philippines facing the vast Pacific Ocean. The mixed-methods of research were employed in the study primarily using documentary analysis, Key Informant Interview (KII) and focus group discussions (FGD). Results show that there was an increasing trend for the past four years in the incidence of preventable diseases, such as hypertension, trauma, all types of wounds and upper urinary tract infection and increasing rate in pre-natal mortality even when infant deliveries were no longer permitted at home but, rather, done in hospitals or RHU with basic emergency maternal obstetric and neonatal care (Bermonc) facilities; and an increasing rate in the incidence of diseases in infant mortality which can be associated to hygiene, (e.g. diarrhea). The provincial government, in response to identified gaps in health programs of the province, crafted a Province-wide Investment Plan for Health (PIPH) that transformed local plan into multi-sectoral endeavor that involved unified efforts of all the sectors. However, despite all the efforts, there are still cases identified in the health status indicators like pre-natal mortality that remain to be high. Health Programs of the department of health $(\mathrm{DOH})$ being implemented along with to service delivery of the RHU in the 11 towns of the province include intensified disease prevention and control; child health; maternal health; lifestyle and risk prevention; and health promotion and advocacy.
\end{abstract}

\section{Keywords}

Health Status and Program Implementation, Service Delivery, 


\section{Introduction}

According to the United Nations Population Division (1996), there is a significant improvement in human health in the last 5 decades wherein the worldwide life expectancy in the 1950s was 46 years. After thirty years, the number increased to 61 years while after almost five decades, the figure rose to 67 years (World Bank, 2001).

According to World Health Organization (2000), infectious diseases, globally, caused 13 million people annually. Notably, the year 1999 saw 2.8 million deaths of people from Acquired Immune Deficiency Syndrome alone (WHO, 2000). Because of a significant increase in global travel, communicable diseases which were geographically confined before have spread across country borders (Brandeau, Sainfort, \& Pierskalla, 2005). Year after year, the world witnesses the emergence of novel infectious diseases (World Health Organization, 2003). In high-income countries, noncommunicable diseases such as heart disease, cerebro-vascular disease (stroke), cancer, and diabetes are the primary cause of death (Murray \& Lopez, 1996). In low-income countries, malnutrition remains a serious health problem, whereas in high-income countries, obesity is increasingly becoming a health problem (Brandeau, Sainfort, \& Pierskalla, 2005).

Strengthening service delivery is crucial to the achievement of the health-related Millennium Development Goals (MDGs), which include the delivery of interventions to reduce child mortality, maternal mortality and the burden of HIV/AIDS, tuberculosis and malaria. Service provision or delivery is an immediate output of the inputs into the health system, such as the health workforce, procurement and supplies, and financing. Increased inputs should lead to improved service delivery and enhanced access to services. Ensuring availability of health services that meet a minimum quality standard and securing access to them are key functions of a health system (Health Service Delivery, 2010). It also necessitates effective implementation of health program especially in the public sector.

Effective implementation of public health program and policy interventions is crucial in order to achieve intended effects on improving population health or reducing health inequities. If not considerably taken care of, the cost to the health system will be scarce in a time of scarce public health resources (Krisberg, 2010; Cooper \& Kirton, 2009). Much worse, a poorly implemented intervention can quickly erode policy and practice support, creating more challenges to "getting it right" over the longer term in addressing policy of health services in both urban and rural areas (Exworthy, 2008).

For the delivery of public health program to be optimal, the World Health Orgnization (WHO) promotes that integration of health services that encompass 
the management and delivery of quality and safe health services so that people receive a continuum of health promotion, disease prevention, diagnosis, treatment, disease-management, rehabilitation and palliative care services, through the different levels and sites of care within the health system, and according to their needs throughout the life course.

The present study was brought to research attention in order to determine the status in the actual service delivery on health implemented in the Rural Health Units (RHU) of the Province of Catanduanes, which is situated in the Bicol Region of the Philippines. The present study was deemed significant because knowing the status in the actual service delivery on health implemented in the Rural Health Units (RHU) would encourage health sector leaders and policy-makers who are tasked with assessing their health systems to participate in the process to deliberate on ways to assess these key characteristics in their respective locales. It would also stir the scientific curiosity of researchers to continue to look into various methods and measures that would allow health system and health policy progress to be assessed over time, along these important dimensions.

\section{Methodology}

A descriptive-mixed model research was employed in this study where characteristics of variables in particular instances or events are considered and a combination of data collection methods such as documentary analysis and interview are used to seek general trend and provide greater detail (Creswell, Clark, Gutmann, \& Hanson, 2003).

The data gathered were obtained from the Rural Health Units in the eleven (11) towns together with the information from the grassroots and the report of the Provincial Health Office along with the Province-wide Investment Plan for Health. Other sources of data were workers for health in the community like the Barangay Nutrition Scholar Development Workers, the Barangay Health Workers, and the beneficiaries of the health programs through Key Informant Interview (KII) and Focused Group Discussions (FGD) with Municipal Health Officers and other members of the health team in the Rural Health Units (RHU) as key implementers of health programs. It is from these sources that the health programs.

Purposive sampling was used based on the individual knowledge on the issues or capacity and willingness to participate in the research. Some types of research design necessitate researchers to take a decision about the individual participants who would most likely contribute appropriate data, both in terms of relevance and depth (Oliver, 2006).

The list of beneficiaries was taken from the Records of patients/beneficiaries of health programs at the RHU. It is through these data that some beneficiaries were interviewed during the actual consultation at the RHU. In the eleven RHU, all the MHO were part of the FGD together with the midwives and nurses. 


\section{Results and Discussion}

Table 1 presents the number of respondents in the key informant interview and focused group discussions.

Shown in Table 1 are the respondents per municipality in the KII with the beneficiaries of the health programs and in the FGD with the MHO, nurses and midwives in the Rural Health Units.

Two (2) sets of interview guide were prepared one for the implementers for use in the Focused Group Discussion and the other for the Key Informant Interview with the beneficiaries after documentary analysis. KII served as a way to get additional information about health programs in the community from a number of well-connected and informed residents.

The FGD was done with the program implementers in the RHU after the KII. FGD was conducted to explore unknown aspects in the health education situation in the province discussed with health implementers as results of the KII.

Methodological triangulation involves the use of multiple qualitative and/or quantitative methods to study the program. For example, results from surveys, focus groups, and interviews could be compared to see if similar results are being found. If the findings from each of the methods are the same, then validity is established. Triangulation can be used to deepen the researchers' understanding of the issues and maximize their confidence in the findings of qualitative studies.

Table 1. Number of respondents from different municipalities of Catanduanes.

\begin{tabular}{|c|c|c|}
\hline Municipalities & $\begin{array}{l}\text { No. of Respondents } \\
\text { in Key Informant } \\
\text { Interview }\end{array}$ & $\begin{array}{c}\text { No. of Respondents } \\
\text { in Focused Group } \\
\text { Discussions }\end{array}$ \\
\hline Bagamanoc & 8 & 6 \\
\hline Baras & 6 & 6 \\
\hline Bato & 8 & 7 \\
\hline Caramoran & 7 & 8 \\
\hline Gigmoto & 6 & 3 \\
\hline Payo & 7 & 4 \\
\hline San Andres & 8 & 5 \\
\hline San Miguel & 9 & 6 \\
\hline Payo & 7 & 4 \\
\hline Viga & 9 & 8 \\
\hline Virac & 10 & 10 \\
\hline Sub-total & 86 & 70 \\
\hline Grand Total & & \\
\hline
\end{tabular}


This study also utilized the Modified Delphi Technique for the data-gathering procedure. The Delphi Technique is a widely used and accepted method for gathering data from respondents within their domain of expertise. The technique aims to achieve a convergence of opinions on a specific real world issue. The Delphi process has been used in various fields of study such as program planning, needs assessment, policy determination and resource utilization to develop a full range of alternative, explore or expose underlying assumptions as well as correlate judgments' on a topic spanning a wide range of discipline.

This method was utilized during the focused group discussions in which feedbacks from the grassroots were presented to the health program implementers. Through the compilation of responses and information from different views, the researcher was able to have a pool of ideas, which includes comments, clarifications, and strategies and came up with the action plan.

Data presented in the succeeding paragraph came from the Province-wide Investment Plan for Health (PIPH) and some of the interpretations presented were likewise extracted from the documents in the provincial plan. The action of the government followed results of health indicators.

As shown in Table 2, morbidity is the incidence of illnesses. In the last three years (2010-2012), the average morbidity is 75,395 with a rate of 29,601 per 100,000 population. In 2013 , there is $42 \%$ reduction to 44,286 with a rate of 17,158 per 100,000 population.

Table 2. Ten leading causes of morbidity in Catanduanes 3-Year average (2010-2012) versus 2013.

\begin{tabular}{|c|c|c|c|c|c|c|}
\hline \multirow[b]{2}{*}{ Causes of Morbidity } & \multicolumn{2}{|c|}{ 2010-2012 } & \multicolumn{2}{|l|}{2013} & \multicolumn{2}{|c|}{ Percentage } \\
\hline & $\begin{array}{l}\text { Number } \\
\text { of cases }\end{array}$ & $\begin{array}{l}\text { Rate/ } \\
100,000 \\
\text { Population }\end{array}$ & $\begin{array}{l}\text { Number } \\
\text { of cases }\end{array}$ & $\begin{array}{l}\text { Rate/ } \\
100,000 \\
\text { Population }\end{array}$ & Increase & Decrease \\
\hline 1) URTI, all types & 14,441 & 5670 & 8639 & 3347 & - & 40.97 \\
\hline 2) Dental Illnesses, all forms & 14,341 & 5630 & 1272 & 493 & - & 91.24 \\
\hline 3) LRTI, all forms & 3508 & 1377 & 1098 & 425 & - & 69.14 \\
\hline 4) Skin Diseases, all forms & 3014 & 1183 & 385 & 149 & - & 87.40 \\
\hline $\begin{array}{l}\text { 5) Diseases of the Kidney \& } \\
\text { the Urinary Tract }\end{array}$ & 2710 & 1064 & 608 & 236 & - & 77.82 \\
\hline 6) Hypertension & 1902 & 747 & 2577 & 998 & 33.60 & - \\
\hline $\begin{array}{l}\text { 7) Acute Gastro Enteritis, all } \\
\text { forms }\end{array}$ & 1479 & 581 & 940 & 364 & - & 37.35 \\
\hline 8) Trauma & 1402 & 550 & 2089 & 809 & 47.09 & - \\
\hline 9) Bronchial Asthma & 1001 & 393 & 676 & 262 & - & 33.33 \\
\hline 10) Wounds, All Types & 562 & 221 & 2039 & 790 & 257.47 & - \\
\hline Average Morbidity & 75,395 & 29,601 & 44,286 & 17,158 & - & 42.04 \\
\hline Average Population & 254,700 & & 258,100 & & 1.33 & \\
\hline
\end{tabular}

Asia Pac J Island Sust (Formerly Research Digest) Vol. 29 No. 2 July-December 2017. 
Comparing the three average rates from 2010 to 2012 VS 2013, there is marked reduction of morbidity rates in the following diseases as reflected in the same table: $40.97 \%$ reduction of URTI from 5670 per 100,000 to 3347 per 100,000 population; $91.24 \%$ reduction of Dental illnesses from 5630/100,000 population to $493 / 100,000$ population; $69.14 \%$ reduction of LRTI from $1377 / 100,000$ population to $425 / 100,000$ population; 77.82 reduction on the Diseases of the Kidney \& the Urinary Tract from 1064/100,000 population to 236/100,000 population; 37.35\% reduction from AGE, all forms from 581/100,000 population to $364 / 100,000$ population; $33.33 \%$ reduction of Bronchial Asthma from $393 / 100,000$ population to $262 / 100,000$ population.

There is marked increased in the following illnesses: $33.30 \%$ increase in Hypertension from $747 / 100,000$ population to $998 / 100,000$ population; $47.09 \%$ increase in trauma from $550 / 100,000$ population to $8009 / 100,000$ population; and $257.47 \%$ on wound all types from $221 / 100,000$ population to $790 / 100,000$ population.

In 2013, URTI remains the leading cause of illness, now followed by hypertension, trauma and wound all types.

Maternal Death is the death of a woman while pregnant or within 42 days after pregnancy termination. The quality of health care during pregnancy and childbirth play significant role in reducing risks that may lead to maternal death.

Maternal Death Review (MDR) undertaken by the Provincial Review Team (PRT) enables the PHO, Hospitals and RHUs generate accurate data. Through this, direct and indirect causes of maternal deaths, the factors surrounding the death were determined. This allowed concerned RHUs and ILHZs develop appropriate interventions to address gaps. However, the trends in maternal mortality rates showed steady increase in the last three years (2010-2012) from 122 per 100,000 LB to 152 per 100,000 LB. The three year provincial average at 138 per $100,000 \mathrm{LB}$ has increased by $25 \%$ to $168 / 100,000 \mathrm{LB}$ and is still very far behind from both the $2010 \mathrm{NOH}$ at 90 per 100,000 LB and the MDG targets at 52 per 100,000 LB. These data are alarming despite the establishment of BEmONC facilities in the province. There is therefore a need to sustain tracking of progress of maternal health initiatives under the Second Women's Health Safe Motherhood Project (WHSMP 2) and review the local health delivery system on a regular basis.

The number one leading cause of maternal deaths is hypertension. This is followed by complications of labor that can often be effectively treated in a health system that provides skilled personnel facilities to handle emergencies when they occur and post-partum care. This underscores the importance of having a skilled attendance at delivery. Research has shown that approximately $80 \%$ per cent of maternal deaths could be averted if women had access to essential maternity and basic health-care services.

The health status indicators presented above are the results of the interventions instituted by the Provincial Government through the Province-wide Investment Plan for Health from CY 2010-2012. The health outcomes were cre- 
dited to the health sector reforms of the province.

The devolution of health services to the LGUs by virtue of the LGC of 1991, had posed extremely difficult challenge to the LGU, which had eight (8) hospitals and a RHU in every municipality. Budget allocations from the national government creating mismatches to achieve operational efficiency, quality health services for a long time became impractical until reform initiatives were introduced by the DOH. In 2008-2012, the provincial government of Catanduanes was included in the Fl provinces to avail of the opportunities to improve service delivery to accomplish the health systems goals of better health outcomes, better healthcare financing and responsive health systems. Critical reforms were laid out in the Province wide Investment Plan for Health (PIPH). The PIPH served as the roadmap for health reforms and is a five year medium term plan covering the years 2008 to 2012 .

In her message in the Province-wide Investment Plan for Health, the Provincial Governor Hon. Araceli Wong said, "Our health gains as reflected in the health outcomes were credited to the implementation of the health sector reforms in the province. It gave me the challenge to pursue innovative and responsive interventions in the province-wide health systems initiated by my predecessors. This commenced immediately on my first day in the office as Provincial governor."

The implementation of PIPH yielded significant improvements in the health status of the people of Catanduanes. These were reflected in the achievements of the millennium development goals. However, reform initiatives need to be sustained, institutionalized and scaled up. The province has now PIPH for 2014-2016 as a new strategy that looked into the pitfalls of the original approach. For PIPH 2 to be more efficient and responsive, gaps were identified and accordingly evaluated for improvement.

The provincial government, in response to the gaps in health of the province crafted a province-wide Investment Plan for Health (PIPH) that transformed local plan into sector endeavor that involved unified efforts of the entire sector towards achieving the global commitment of the Millennium Development Goals (MDG) and the National Objectives for Health (NOH). The Provincial Local Government Unit (PLGU) assumed stewardship through the Provincial Health Office (PHO) and the Local Implementation and Coordination Team (LICT).

The PHO conducted various workshops and write shops involving health leaders and decision makers in all municipalities formulating the vision, mission, goals, SWOT and gaps analysis, objectives, goals settings, strategic interventions within the framework of the Universal Health Care strategic thrust. The LGUs also used score cards to easily see the results of programs as compared with national targets on health.

To respond to the foregoing gaps, the PIPH 2 investments required a total of Php 1,013,404,877.52. It shall utilize the four strategic instruments, namely: Financing, Service Delivery, Policy Standards and Regulation. The provincial gov- 
ernment also is conducting several interventions being implemented for improved health status along the different indicators.

Table 3 the ten leading causes of mortality in three year average, 2010 to 2012, with the number of cases and rate per 100,000 population compared with the number of cases for 2013 and the rate per 10,000.

In the last three years (2010-2012), the average mortality is 1635 with a rate of 642 per 100,000 population. In 2013, overall there is $11 \%$ increase to 1853 with a rate of 718 per 100,000 population. Comparing with the three average rate from 2010 to 2012 VS 2013, there is an increase in mortality rates in the following diseases as reflected in Table 3: e.g. 6.36\% increase of Pneumonia from 110 per 100,000 to 117 per 100,000 population; $62.07 \%$ increase of Cancer all Forms from $29 / 100,000$ population to $47 / 100,000$ population; $120 \%$ increasing Diabetes Mellitus. There is marked reduction in the following leading causes of deaths: $36.36 \%$ reduction of Hypertension from $77 / 100,000$ population to $49 / 100,000$ population; $54.29 \%$ reduction in Diseases of the Heart from 70/100,000 population to $32 / 100,000$ population, $47.37 \%$ reduction in Senility/Debility from $38 / 100,000$ population to $20 / 200,000$ population; $24 \%$ reduction in TB all forms from $25 / 200,000$ population to $19 / 100,000$ population; $81.25 \%$ reduction in Bronchial Asthma from $16 / 100,000$ population to $3 / 100,000$ population; $71.43 \%$ reduction in Traumas/Injuries from $14 / 100,000$ population to $4 / 100,000$ population; $41.67 \%$ reduction in Prematurity from $12 / 100,000$ population to $7 / 100,000$ population.

Table 3. Leading causes of mortality, in Catanduanes 3-Year average (2010-2012) VS 2013.

\begin{tabular}{|c|c|c|c|c|c|c|}
\hline \multirow[b]{2}{*}{ Causes of Mortality } & \multicolumn{2}{|c|}{ 2010-2012 } & \multicolumn{2}{|c|}{2013} & \multicolumn{2}{|c|}{ Percentage } \\
\hline & $\begin{array}{c}\text { Number of } \\
\text { Cases }\end{array}$ & $\begin{array}{l}\text { Rate/10,000 } \\
\text { Population }\end{array}$ & $\begin{array}{c}\text { Number of } \\
\text { Cases }\end{array}$ & $\begin{array}{l}\text { Rate } / 10,000 \\
\text { Population }\end{array}$ & Increase & Decrease \\
\hline 1) Pneumonia & 280 & 110 & 302 & 117 & 6.36 & - \\
\hline 2) Hypertension & 196 & 77 & 126 & 49 & - & 36.36 \\
\hline 3) Diseases of the Heart & 179 & 70 & 82 & 32 & - & 54.29 \\
\hline 4) Senility/Debility & 96 & 38 & 51 & 20 & - & 47.37 \\
\hline 5) Cancer, all forms & 74 & 29 & 122 & 47 & 62.07 & - \\
\hline 6) TB All Forms & 64 & 25 & 48 & 19 & - & 24.0 \\
\hline 7) Bronchial Asthma & 40 & 16 & 8 & 3 & - & 81.25 \\
\hline 8) Traumas/Injuries & 37 & 14 & 10 & 4 & - & 71.43 \\
\hline 9) Prematurity & 30 & 12 & 17 & 7 & - & 41.67 \\
\hline 10) Diabetes Mellitus & 12 & 5 & 28 & 11 & 120.0 & - \\
\hline Average Mortality & 1635 & 642 & 1853 & 718 & 11.84 & - \\
\hline Average Population & 254,700 & & 258,100 & & 1.33 & - \\
\hline
\end{tabular}


Table 4 reflects that the provincial average for neonatal mortality in the last three years (2011-2012) is 22 deaths at a rate of 3 per 1000 LB. Comparing with the 2013 performance, it has $41 \%$ reduction to 22 cases at a rate of $3 / 1000 \mathrm{LB}$ to 13 cases $(2 / 1000 \mathrm{LB})$.

Pneumonia as the leading cause has increased to $47.37 \%$ from 3.3 cases or $0.57 / 1000 \mathrm{LB}$ in the 3 year average 2010-2012 to 5 cases $(0.84 / 1000 \mathrm{LB})$ in 2013. As shown in Table 4, the neonatal mortality in 2013 at $2 / 1000 \mathrm{LB}$ has improved from the 3 year average (2010-2012) performance at 3 per 1000 LB and even better than the $2010 \mathrm{NOH}$ target at 10 per $1000 \mathrm{LB}$.

Causes and determinants of neonatal deaths and stillbirths differ from those causing and contributing to post-neonatal and child deaths. Neonatal deaths and stillbirths stem from poor maternal health, maternal health, and inadequate care during pregnancy, inappropriate management of complications during pregnancy and delivery, poor hygiene during delivery and the first critical hours after birth, and lack of newborn care. Several factors such as women's status in society, their nutritional status at the time of conception, early childbearing, too many closely spaced pregnancies and harmful practices, such as inadequate cord care, letting the baby stay wet and cold, discarding colostrum and feeding other food, are deeply rooted in the cultural fabric of societies and interact in ways that are not always clearly understood. In Catanduanes, for the last two years (2011-2012) and in 2013 infectious Diseases such as Pneumonia (1 $\left.{ }^{\text {st }}\right)$, Septicemia, Cellulitis, and AGE are the leading causes of neonatal deaths probably due to harmful practices that lead to infections. Babies born prematurely ranks $2^{\text {nd }}$; congenital malformations $3^{\text {rd }}$. Overall, there are less than one death per disease entity and three neonatal deaths per 1000 LB. Reducing neonatal deaths is, therefore, an essential step towards reducing under-five mortality.

Table 4. Child mortality, leading causes, Catanduanes, 2010-2012 (Under-5) 3-Year average VS 2013.

\begin{tabular}{|c|c|c|c|c|c|c|}
\hline \multirow{2}{*}{$\begin{array}{c}\text { Illnesses } \\
\text { Causing Deaths }\end{array}$} & \multicolumn{2}{|c|}{$\begin{array}{l}3 \text { Year Average } \\
(2010-2012)\end{array}$} & \multicolumn{2}{|r|}{2013} & \multicolumn{2}{|c|}{ Percentage } \\
\hline & No. & Rate/1000LB & No. & Rate/1000LB & Increase & Decrease \\
\hline Pneumonias & 80 & 14 & 21 & 3.53 & - & 74.79 \\
\hline Diarrhoeas, All Causes & 11 & 1.98 & 3 & 0.50 & - & 74.75 \\
\hline Malnutrition & 7 & 1.3 & 2 & 0.34 & - & 73.85 \\
\hline Congenital Anomalies & 5 & 0.9 & 0 & 0 & - & 100.0 \\
\hline Sepsis & 5 & 0.9 & 2 & 0.34 & - & 62.22 \\
\hline Dengue H Fever & 1 & 0.2 & 0 & 0 & - & 100.0 \\
\hline Cerebral Palsy & 1 & 0.2 & 0 & 0 & - & 100.0 \\
\hline Accident & 1 & 0.2 & 0 & 0 & - & 100.0 \\
\hline Acute Febrile Illness & 1 & 0.2 & 0 & 0 & - & 100.0 \\
\hline Live Births & 5779 & & 5952 & & 2.99 & \\
\hline Total Deaths & 36 & 6 & 55 & 9.24 & 54.0 & \\
\hline
\end{tabular}


Table 4 presents the Infant Mortality in Catanduanes for 3 year average vs the neonatal mortality in 2013. Rate per 1000 Live Births is also presented.

Infant Mortality is the number of deaths among infants (below one year of age) per 1000 LB. In Catanduanes, there is an increase of infant mortality rate from the three year average (2010 to 2012) by $4 \%$ at 51 cases or 8.8/1000LB to 53 cases in 2013 or $8.9 / 1000 \mathrm{LB}$.

As reflected in Table 4, the leading causes of infant mortality in the last three years (2010-2012) and 2013 are infectious of these Pneumonias ranks $1^{\text {st }}$, with a rate at $6 / 1000 \mathrm{LB}$. This is better though than the NOH target of 33/1000LB. Diarrhea, in all forms, ranked 2nd with a rate (2010-2012) at 4 per $1000 \mathrm{LB}$ in the last three years but no longer of the leader cause in 2013. The average number of infant deaths in 2013 is 53 . This means that there are 9 infant deaths per $1000 \mathrm{LB}$.

Table 5 presents the Infant Mortality in Catanduanes for a 3 year average of the Under 5 Mortality and for 2013. Rate per 1000 Live Births is also presented. Under-Five Mortality Rate is the number of deaths below age five per $1000 \mathrm{LB}$ during a given period. The three year trend in the Under-5 Mortality as shown in Table 4 demonstrates increase by $54 \%$ from the three year average (2008 to 2010) at 6/1000LB to 9/1000LB in 2013. The leading causes of maternal mortality in Catanduanes for average of 3 years, 2010-2012 and the ratio per 100,000 population and is compared with 2013 data. To respond to the foregoing gaps, the PIPH 2 Investments required a total of $\mathrm{Php} 1,013,404,877.52$. It shall utilize the four strategic instruments, namely: Financing, Service Delivery, Policy Standards and Regulation. The provincial government also is conducting several interventions being implemented for improved health status along the different indicators.

Table 5. Maternal mortality, leading causes, Catanduanes 2010-2012, T3-Year average VS 2013.

\begin{tabular}{|c|c|c|c|c|c|c|}
\hline \multirow{2}{*}{$\begin{array}{c}\text { Illnesses } \\
\text { Causing Deaths }\end{array}$} & \multicolumn{2}{|c|}{$\begin{array}{l}3 \text { Year Average } \\
(2010-2012)\end{array}$} & \multicolumn{2}{|r|}{2013} & \multicolumn{2}{|c|}{ Percentage } \\
\hline & No. & $\begin{array}{c}\text { Ratio/ } \\
100,000 \mathrm{LB}\end{array}$ & No. & $\begin{array}{c}\text { Ratio/ } \\
\text { 100,000LB }\end{array}$ & Increase & Decrease \\
\hline Pregnancy Induced Hypertension & 2.7 & 0.46 & 3 & 50 & 8.70 & \\
\hline Septic Abortion Induced Septic & 2.7 & 0.46 & 0 & 0 & & 100 \\
\hline Uterine Atony & 1.0 & 0.17 & 0 & 0 & & 100 \\
\hline Abruptio Placenta & 1.0 & 0.17 & 0 & 0 & & 100 \\
\hline Postpartum Cardiomyopathy & 1.0 & 0.17 & 0 & 0 & & 100 \\
\hline Ruptured Uterus & 1.0 & 0.17 & 0 & 0 & & 100 \\
\hline Amniotic fluid embolism & 1.0 & 0.17 & 0 & 0 & & 100 \\
\hline Ruptured Eptopic Pregnancy & 1.0 & 0.17 & 0 & 0 & & 100 \\
\hline Chronic Anemia & 0.7 & 0.11 & 0 & 0 & & 100 \\
\hline Retained Placenta & 0.7 & 0.11 & 0 & 0 & & 100 \\
\hline Live Births & 5779 & & 5952 & & 2.99 & \\
\hline Total Deaths & 8 & 138 & 10 & 168 & 21.74 & \\
\hline
\end{tabular}


Table 6 presents the health status indicators and the interventions being done by the Provincial Government.

These measures have been laid out in response to the health status gaps based on the health status indicators. For every health status indicator, various approaches and strategies are being conducted that generally include aspects on service delivery finance, regulation and governance.

Table 6. Response of the provincial government in response to the health status indicators.

\section{HEALTH STATUS INDICATORS}

1) Leading causes of
morbidity

2) Leading causes of mortality

3) Indicators of Child Mortality

a) Perinatal Mortality

b) Neonatal Mortality

c) Infant Mortality

d) Under five Mortality

4) Leading causes of maternal mortality

\section{INTERVENTIONS OF THE PROVINCIAL GOVERNMENT}

- Implementing Health promotion programs

- Expanding National Health Insurance Policy (NHIP) enrolment and increase utilization

- Facility enhancement that shall leverage fund for improved facility capacity to adequately manage the common causes of morbidity

- Fiscal autonomy and income retention schemes for health facilities and government hospitals

- Service package

- Strengthening Health Systems

- Capability building of health care providers

- Intensifying disease surveillance

- Facility enhancement that shall leverage fund for improved facility capacity to adequately manage the common causes of morbidity

- Clustering and referral networks of health facilities on their catchment areas to address the current fragmentation of health services

- Capability building of health care providers

- Intensify disease surveillance

- Promoting universal access to standard child survival package of intervention that include New Born Screening and immunization.

- Enhancing the capacity of service delivery networks as channels of child survival.

- Creating opportunities for communities to overcome barriers to utilization of child survival.

- Harmonizing efforts of DOH, allied agencies and partners in supporting local delivery of child survival services.

- Building the LGUs resolve to adopt and implement child survival strategy.

- Mother-baby friendly facilities.

- Adopting and implementing appropriate guidelines for community-based management of acute malnutrition.

- Creation of policy on standard monitoring, recording \& reporting of nutrition status of at risk population.

- Enhancing capabilities of health workers.

- Promoting facility-based births attended by skilled health professionals catering to specific needs of mother and the newborn

- Increasing competencies of health providers in providing comprehensive health and maternal child health services

- Sustaining health care financing

- Post-partum care package

- Capability building of health care providers 
In the light of the above findings, the following conclusions were drawn. 1) The health status of the province of Catanduanes is determined by 4 indicators; in which there are indicators that include communicable diseases and preventable diseases. If the people will be more aware and informed, these cases can be controlled or lessened through health information and health education and 2) The provincial government is exerting its effort to attain the goals in health through the LGU scorecards that serve as guide for future actions. It has crafted the province-wide investment plan for health to assess health problems, make future plans and strategies, guide the implementers and monitor the health status of the province allotting budget for its implementation. But despite the efforts of the provincial government there is still increasing incidence of some diseases. This implies that continuous assessment of health services and health conditions of residents in the province should be responsive and tailored-fit based on its geographical condition and population demographics. The findings also suggest that constant and cyclical collaborative discussion among health experts, policy makers, provincial leaders, academicians and researchers is crucial in order to address the incidence of other diseases that cause death the death of the provincial populace, thereby increasing the likelihood of these people to contribute to their community goals.

\section{Future Directions}

From the findings and conclusions of the study, the following are recommended 1) Collaborative efforts with new strategies and approaches which must be established to improve results of health indicator; 2) Additional funding for health including funds for research on health; and 3) Convergence for Health in the province of Catanduanes with the academe and other sectors which can contribute to health outcomes.

\section{Conflicts of Interest}

The author declares no conflicts of interest regarding the publication of this paper.

\section{References}

Brandeau, M. L., Sainfort, F., \& Pierskalla, W. P. (2005). Health Care Delivery: Current Problems and Future Challenges. In Operations Research and Health Care (pp. 1-14). Berlin: Springer. https://doi.org/10.1007/1-4020-8066-2_1

Cooper, A. F., \& Kirton, J. (2009). Innovation in Global Health Governance: Critical Cases. Surrey: Ashgate Publishing Ltd.

Creswell, J. W., Clark, V. L. P., Gutmann, M. L., \& Hanson, W. E. (2003). Advanced Mixed Methods Research Designs. In A. Tashakkori, \& C. Teddliue (Eds.), Handbook of Mixed Methods in Social and Behavioral Research (pp. 209-240). Thousand Oaks, CA: Sage.

Exworthy, M. (2008). Policy to Tackle the Social Determinants of Health: Using Conceptual Models to Understand the Policy Process. Health Policy Plan, 23, 318-327. 
https://doi.org/10.1093/heapol/czn022

Health Service Delivery (2010).

https://www.who.int/healthinfo/systems/WHO_MBHSS_2010_section1_web.pdf

Krisberg, K. (2010). Budget Cuts Straining Capacity of Public Health Departments: Services in Demand. Nation's Health, 40, 1-16.

Murray, C. J. L., \& Lopez, A. (1996). The Global Burden of Disease: A Comprehensive Assessment of Mortality and Disability from Diseases, Injuries, and Risk Factors in 1990 and Projected to 2020. Boston, MA: Harvard School of Public Health.

Oliver, P. (2006). Purposive Sampling. In V. Jupp (Ed.), The Sage Dictionary of Social Research Methods (pp. 244-245). Thousand Oaks, CA: Sage Publication, Inc.

United Nations Population Division (1996). Demographic Indicators, 1950-2050 (The 1996 Revision). New York: United Nations.

World Bank (2001). Life Expectancy Learning Module. World Bank Development Education Program Web.

World Health Organization (2000). Report on the Global HIV/AIDS Epidemic June 2000.

World Health Organization (2003). Severe Acute Respiratory Syndrome (SARS)_MultiCountry Outbreak-Update 26. http://www.who.int/csr/don/2003_04_10/en 